\title{
La pluma contra las Cortes y el Trono. La prensa y el desmontaje del liberalismo hispánico en el Perú, 1821-1824
}

\author{
por \\ Víctor Peralta Ruiz \\ CCHS-CSIC, Madrid
}

A través del análisis del discurso de la prensa del periodo de la independencia, básicamente publicada en Lima, se demostrará cómo pudo extirparse el liberalismo hispánico de la cultura política peruana. Se argumentará que el segundo constitucionalismo español conocido como Trienio Liberal fue fácilmente representado por los periódicos no solo como un periodo de intolerancia a la independencia hispanoamericana sino como un gobierno de la plebe dispuesta a acabar con la nobleza ilustrada y la religión y un sistema en que los serviles absolutistas y los liberales moderados y exaltados compartían con Fernando VII una congénita conducta despótica. El artículo se divide en tres partes que se corresponden, sucesivamente, con la etapa del Protectorado, el establecimiento del Congreso Constituyente y la dictadura de Simón Bolívar.

Palabras Clave: Prensa; Trienio Liberal; liberalismo hispánico; Perú; Protectorado; Bernardo Monteagudo; Congreso Constituyente; José Faustino Sánchez Carrión; Hipólito Unanue.

\section{INTRODUCCIÓN}

La cultura política del periodo de la independencia tiene aún muchos temas pendientes de trabajar, a pesar de los avances recientes ${ }^{2}$. Las investigaciones que han profundizado en las ideologías que se confrontaron durante la coyuntura independentista (republicanismo versus monarquía constitucional) han

1 Este trabajo forma parte del Proyecto de Investigación I+D financiado por el Ministerio de Ciencia e Innovación de España Tiempos de desconcierto. Política y sociedad en la Independencia del Perú, 1820-1824, Referencia HAR2008-03259.

2 Aljovín, 2000. Aljovín y Jacobsen (eds.), 2007. Chiaramonti, 2005. Peralta, 2010. 
demostrado que la prensa fue el vehículo fundamental para convencer a la opinión pública de las bondades de ambos sistemas de gobierno. Martínez Riaza encuentra que los periódicos doctrinarios que optaron por la forma republicana de gobernar supieron convencer al público de que el sentimiento de patria y de nación se afianzaría bajo un liberalismo asociado con instituciones representativas y democráticas que solo la república podía proporcionar ${ }^{3}$. Posteriormente, Carmen McEvoy añade que el éxito de la propaganda sostenida por el político republicano José Faustino Sánchez Carrión y sus seguidores se debió a la identificación que hicieron estos de la ciudadanía, el civismo y la civilidad con lo que la sociedad y las instituciones de Estados Unidos cultivaban. Fue fundamental para afianzar esta creencia la divulgación en Lima de la obra Common Sense de Thomas Paine en una edición traducida por el «indígena del Perú» Anselmo Nateiu, anagrama que se ha supuesto utilizó el diputado Manuel José de Amunátegui ${ }^{4}$. Paine fue un inglés que fervorosamente defendió los valores políticos y morales de la democracia estadounidense. Afirma McEvoy que por esa influencia la comunidad política imaginada por Sánchez Carrión «además de estar asociada a un elemento tan concreto como la propiedad, estableció, como lo hicieron sus predecesores, estrechos vínculos con el honor y con la virtud. El ciudadano propietario, honorable y virtuoso fue el puntal principal del republicanismo peruano post-Independencia» ${ }^{5}$.

Uno de los vacíos que todavía se advierte en la reflexión historiográfica del paso de la monarquía a la república es saber si las formas de representación que los políticos peruanos formularon con relación al liberalismo hispánico estuvieron asociadas con el discurrir en España del llamado Trienio Liberal, periodo este que se corresponde con el momento en que los liberales impusieron en marzo de 1820 a Fernando VII la monarquía constitucional y que concluyó violentamente en octubre de 1820 con la restauración del absolutismo ${ }^{6}$. A diferencia de lo ocurrido tras la restauración absolutista en 1814, cuando el liberalismo hispánico en el Perú fue prohibido y silenciado por el gobierno para volver al statu quo previo a 1808, entre 1821 y 1823 el gobierno del Protectorado y después el Congreso Constituyente a través de la prensa no se desentendieron de la realidad española y siguieron con cierto detalle lo que allí estaba ocurriendo. Se argumentará que la ruptura con el liberalismo hispánico, que fue la matriz de la transformación de la cultura política peruana en la época de las Cortes de Cádiz, se sustentó en la forma cómo se informó, básicamente en tér-

\author{
3 Martínez Riaza, 1985: 45-60. \\ 4 Nateiu, 1821. \\ 5 McEvoy, 2002: 62-63. \\ 6 Gil Novales, 1980. Fernández Sarasola, 2001. La Parra, 2007.
}


minos negativos, sobre el discurrir del segundo momento liberal español. Se postulará que los periódicos, y muy en especial la Gaceta de Gobierno publicada entre 1821 y 1823 , contribuyeron a derruir los últimos cimientos discursivos de la cultura política doceañista que sobrevivió a la purga absolutista practicada en la época del virrey Pezuela.

\section{UNA BREVE DEFENSA DE LA MONARQUÍA CONSTITUCIONAL}

La segunda entrada en vigor de la carta gaditana en Lima fue cronológicamente breve, de septiembre de 1820 a julio de 1821, y su impacto entre la población muy inferior en comparación con lo ocurrido en la época en que estuvieron vigentes las Cortes de Cádiz. La ceremonia pública de juramentación de la Constitución fue, en palabras del propio virrey Pezuela, fría y deslucida. Ese desinterés tiene su correlato en la preocupación que manifestaba la población ante el desembarco en Pisco de la Expedición Libertadora del general José de San Martín que se sumaba al bloqueo naval de El Callao impuesto por los navíos comandados por Lord Cochrane. En ese clima de incertidumbre, el virrey Pezuela decidió instrumentalizar el momento constitucional con el propósito de contener la ofensiva patriota. En la conferencia de Miraflores el virrey, siguiendo las instrucciones de la Península, ofertó a San Martín el cese de hostilidades, la apertura de negociaciones y un indulto general si este acataba la Constitución y reconocía la soberanía de Fernando VII. San Martín, como era de esperar, rechazó tal proposición al considerar que tanto el monarca como el virrey actuaban movidos por un instinto de conservación política antes que por un real convencimiento en las bondades del liberalismo. Nada había que negociar con España si no era sobre la base del reconocimiento de la independencia peruana. Ante este fracaso anunciado, Pezuela procedió a cumplir con el precepto constitucional y nombró una Junta Preparatoria cuya misión fue restablecer la Diputación Provincial de Lima. Simultáneamente, el virrey fue de la opinión de que el cabildo constitucional que se estableciera fuese el mismo que estuvo en vigencia en 1814. Pero los capitulares perpetuos lograron convencerle de que debían celebrarse nuevas elecciones. Así se produjo y el 7 de diciembre de 1820 quedó constituido el Ayuntamiento constitucional con sus dos alcaldes, el conde de San Isidro y José María Galeano ${ }^{7}$. La entrada en vigor de la Constitución también supuso la definitiva abolición de la Inquisición. El hecho de que la libertad de imprenta no fuese inmediatamente restablecida hizo suponer que Pezuela no quiso acatar la Constitución. Este

\footnotetext{
7 Gamio Palacio, 1971. Paniagua, 2003. Sobrevilla, LXIX/246 (Madrid 2009): 101-128.
} 
supuesto queda desmentido por una simple constatación: el restablecimiento de la Constitución en España no supuso el inmediato retorno de la libre impresión de opiniones políticas.

En efecto, las Cortes reunidas en Madrid dedicaron su primera legislatura ordinaria a debatir las reformas que se debían introducir al decreto de publicar impresos políticos. Ello explica que el decreto de Libertad de Imprenta fuese recién sancionado en la sesión del 22 de octubre de 1820. En general, esta nueva ley mantuvo los principios fundamentales del decreto del 10 noviembre de 1810 aunque, en esta ocasión, se fijó con mayor precisión las facultades de la Junta de Protección de la libertad de imprenta y las penas a que se hacían acreedores los que abusaban de tal derecho ${ }^{8}$. El decreto llegó a la capital peruana a fines de enero de 1820 y la noticia casi coincidió con el momento en que un grupo de militares reunido en Aznapuquio depuso a Pezuela y nombró como virrey al brigadier José de la Serna. Lo anterior explica que la Gaceta del Gobierno de Lima fuese el único periódico que Pezuela autorizase editar en los últimos meses de su gobierno constitucional. También permite entender que, circunstancialmente, le correspondiese al virrey de facto La Serna acatar y aplicar el decreto de Madrid. Por esto último en Lima comenzó a publicarse el 13 de febrero de 1821 El Triunfo de la Nación, periódico editado en la imprenta de Guillermo del Río y cuya entrega por subscripción se hacía los martes y viernes. Un mes después comenzaron a circular El Depositario, a cuenta del comerciante riojano Gaspar Rico, y El Censor Económico editado en la imprenta de Manuel Peña.

Resulta indispensable saber cuánto tardaba en publicarse una noticia u ordenanza procedente de la España liberal. Se puede dar una respuesta tentativa de entre seis y nueve meses. Este último es el lapso de tiempo que tardó El Triunfo de la Nación en dar a conocer la Real Orden del 27 de junio de 1820 en la que Fernando VII exculpaba a la Audiencia de Charcas por el estallido de la Revolución del 25 de mayo de 1809 ya «que todos sus procedimientos fueron dictados por la lealtad más acendrada, y el más recomendable celo en defensa de los derechos de S. M. y de la integridad de la nación ${ }^{9}$. La difusión del nuevo Reglamento para la Libertad Política de la Imprenta aprobado en Madrid se hizo en El Triunfo de la Nación el 24 de abril y el 8 de mayo de 1821, es decir, seis meses después de aprobarse en las Cortes. Los redactores de este periódico, entre los que estuvo el brigadier Andrés García Camba, pusieron especial

8 Gómez-Reino, 1977: 109-111.

9 El Triunfo de la Nación, 16 de febrero de 1821. Ese también fue el desfase temporal que se produjo entre el juramento de la Constitución en Madrid ( 9 de marzo de 1820) y la recepción de esta real orden por Pezuela (4 de septiembre de 1820). 
cuidado en «ilustrar a la población» sobre los alcances de esta disposición. En primer lugar se destacó su preeminencia sobre las antiguas disposiciones en materia de publicaciones prohibidas hechas por la abolida Inquisición. Así, en un artículo publicado en la primera página del número 12, se daba a conocimiento de los lectores que el gobierno constitucional había corregido una circular impresa redactada por los gobernadores de la diócesis de Santander en el que pretendían renovar las penas inquisitoriales contra los lectores de libros prohibidos. «El Amante de la Ilustración», seudónimo de un articulista de este periódico, destacaba que el rey asesorado por la Junta Provisional y el Consejo de Estado «se ha servido declarar que los referidos gobernadores de la diócesis de Santander se han excedido de sus facultades, mandando con arreglo al art. 32 del decreto de las Cortes de 10 de junio de 1813, sobre la libertad de imprenta, que los gobernadores remitan a la Secretaría del Despacho de la Gobernación de mi cargo todos los ejemplares de la circular, recogiendo a este efecto el que habían expedido» ${ }^{10}$. Más adelante, El Triunfo reproducirá un artículo de El Constitucional de Madrid en el que su articulista asocia a los que aún añoran la Inquisición con los amantes del despotismo: «ellos abogaban por la Inquisición ¿y porqué pensáis que lo hace? Porque saben bien que existiendo este tribunal, como ellos quieren, ninguno se atreverá a descubrir los delitos de las autoridades; porque con él desaparecerá la libertad de escribir; porque con él morirá la Constitución de la monarquía» ${ }^{11}$.

De Fernando VII como monarca constitucional en El Triunfo de la Nación se publicó una anónima «carta particular» originada en Madrid en la que se le elogia su premura para corregir los errores de su pasado absolutista. Se calificaba como sincero su juramento como monarca liberal y se destacaba como prueba de ello su Real Decreto de 26 de marzo de 1820, en el que ordenó castigar con penas de cárcel a los enemigos de la Constitución. El articulista hasta se hizo eco de un rumor que deseaba se cumpliese durante el segundo año de las Cortes de Madrid: «se dice que este próximo congreso va a declarar nulo todo lo actuado entre el 4 de mayo de 1814 y el 9 de marzo de 1820 . De este modo se podrán remediar en cierto modo las desatinadas medidas que nos han puesto al borde casi del abismo ${ }^{12}$. Por lo demás, un autor prohibido hasta entonces en España y América como el abate de Pradt, era motivo de una elogiosa reseña en El Triunfo de la Nación por destacar en su obra L'injustice á la fin produit l'independance, que la influencia moral de la España liberal sobre Portugal tarde o temprano provocaría un cambio político en esta última sin que

10 El Triunfo de la Nación, 23 de marzo de 1821.

11 Ibidem, 10 de abril de 1821.

12 Ibidem, 27 de marzo de 1821. 
aquella necesitara conquistar a esta «porque hay incompatibilidad entre ambos pueblos». El editor añadió a lo dicho por el publicista francés que Portugal por depender del Brasil, por residir allí el monarca, podía subsistir aislado de las luces del liberalismo «hasta que los rápidos progresos que el mismo por sí vea que hace la España en su carrera política [...] le hagan despertar de su preocupación y desear unánimemente seguir el orden dictado por la naturaleza, por Dios mismo» ${ }^{13}$. Hasta en la polémica que tuvo este periódico con el Censor Económico, que defendía la necesidad de que se solicitase al rey el comercio libre con los ingleses, «El amante de la verdad» se valió del liberalismo hispánico vigente para replicarle. Concretamente, le recordó que el artículo 172 de la Constitución que trataba de las restricciones de la autoridad del monarca, especificaba que:

no puede el rey hacer alianza ofensiva, ni tratado especial de comercio con ninguna potencia extranjera sin el consentimiento de las cortes. Estas son peruanos las leyes, que tenemos regladas en el código vigente [...] es absurdidad pretenderlo aquí, y estar insistiendo en especie tan chocante. Si el Censor, se hubiera sujetado a la cláusula final del papel que ha querido desairar, sabría que esto toca a las supremas potestades, y no habría caído en este vergonzoso incurable desacierto ${ }^{14}$.

Más adelante, el periódico publicará en varios números el extenso reglamento de comercio exterior y marítimo sancionado por las Cortes con el que creyó ver confirmada su postura de que solo esta instancia tenía legalmente la potestad de dar una medida de ese calado.

El Triunfo de la Nación se propuso recordar a una serie de personalidades representativas del primer liberalismo hispánico que en España y en el Perú defendieron la carta política en Cádiz pese a las represalias experimentadas después. En el caso español ese fue el caso de Juan Díaz Porlier, marino que combatió en la guerra de la independencia y que en septiembre de 1815 conspiró para restablecer la Constitución, lo que le condujo a ser ajusticiado por orden de Fernando VII ${ }^{15}$. En una pequeña miscelánea se dio cuenta que el 4 y 5 de mayo de 1820 se celebraron en La Coruña sus exequias. En la noticia se le calificaba de héroe liberal y se recordaba que el cortejo fúnebre,

cuando llegó en frente de la horca, que se había plantado en el sitio acostumbrado, la niña que figuraba la patria se levantó, recitó una octava y al concluirla se vio arder aquel instrumento afrentoso del martirio del héroe asturiano, y salir volando del carro seis blancas palomas con largas cintas en que se leía: viva el triunfo de la libertad ${ }^{16}$.

13 Ibidem, 30 de marzo de 1821

14 Ibidem, 3 de abril de 1821.

15 Su biografía ha sido abordada por Barthèlemy, 1995.

16 El Triunfo de la Nación, 23 de febrero de 1821. 
En el caso peruano se destacó la figura del ex fiscal de la Audiencia de Lima, el chileno Miguel de Eyzaguirre. El Triunfo le rindió un homenaje tras darse a conocer su fallecimiento en Trujillo el 6 de mayo de 1820, y de él se destacó, aparte de su apego a la Constitución, su conducta nada cortesana ni aduladora hacia el virrey Abascal. El póstumo reconocimiento al malogrado líder del partido Constitucional limeño en 1813 y ex regidor del primer Ayuntamiento Constitucional procuraba reparar la proscripción pública que este experimentó después de abolirse la Constitución ${ }^{17}$. De Eyzaguirre comentará el incógnito autor escondido bajo las siglas J. H. que «diga lo que quiera Abascal contra este purísimo, integérrimo, e irreprehensible ministro, su celo no es bueno, sino muy malo, pésimo...» ${ }^{18}$.

El Triunfo de la Nación continuó su alegato por un retorno al statu quo previo a la restauración absolutista con un ensayo político sobre el espíritu público de las naciones en el que por igual se rechazaba el gobierno democrático y el aristocrático por no contener las virtudes públicas que eran innatas en una monarquía constitucional. Partiendo del axioma de que el carácter nacional se modifica según los diferentes grados de libertad que permite una Constitución, el articulista resume que la historia de España «presenta en su historia muchos ejemplos palpables de esta verdad, pero ninguno más ilustre que el de la reciente revolución [de 1820]» ${ }^{19}$. El afianzamiento del carácter nacional que ha supuesto el restablecimiento de la Constitución de Cádiz lo resume el articulista en el arraigo de tres valores: 1) sometimiento del gobierno de los hombres al imperio de las leyes, 2) establecimiento de una virtud severa sin lisonja ni deleites y 3) primacía del bien público sobre el particular.

¿Secundó El Depositario el discurso periodístico de El Triunfo de la $\mathrm{Na}$ ción confeccionado para restablecer el entusiasmo popular en Lima por el liberalismo hispánico? Según Martínez Riaza en los primeros números de El Depositario, Gaspar Rico se mostró convencido de que la nueva etapa constitucional reconciliaría a los españoles europeos y americanos, pero a medida que el cerco de las tropas de San Martín sobre Lima se fue estrechando, este comenzó a cuestionar la validez del constitucionalismo y terminó renegando de su pasado liberal ${ }^{20}$. Ya posteriormente, en su etapa más recalcitrantemente antiliberal, El Depositario acusará a El Censor de pretender conciliarse con los patriotas $^{21}$. De otro lado, cabe destacar que en el interior de estos tres periódi-

17 Peralta, 2002: 122-127.

18 El Triunfo de la Nación, 8 de junio de 1821.

19 Ibidem, 12 de junio de 1821.

20 Martínez Riaza, 1985: 43.

21 Ibidem, 1985: 45. 
cos las polémicas fueron escasamente doctrinarias. Por todo ello, la capacidad de esta prensa realista y liberal de orientar políticamente la opinión pública limeña fue mucho menor que el efecto producido por El Peruano, El Satélite del Peruano o El Peruano Liberal en la primera época de vigencia de la Constitución. Además, El Triunfo de la Nación debió perder gran parte de su popularidad entre la población limeña como resultado de su enfrentamiento con el Ayuntamiento Constitucional de Lima en junio de 1821. Este hecho lo suscitó la discrepancia de los alcaldes con la decisión del virrey La Serna de no renovar el armisticio logrado en las negociaciones de Punchauca con el general San Martín. A través de una representación los capitulares limeños exigieron al virrey que hiciese todo lo posible por lograr una paz negociada en vez de dar una salida bélica al asedio que estaba sometida la capital. La reacción de El Triunfo de la Nación en contra de la representación de los alcaldes fue feroz y hasta se pidió en sus páginas un castigo ejemplar contra los autores de la misma a los que se calificó de subversivos. El Triunfo de la Nación se editó hasta el 29 de junio de 1821 y en su último número dio muestras de un «desaliento tan notorio en las miras de los editores que sus últimos números están consagrados a una disertación sobre teatro, una poesía necrológica y un ensayo de Locke» ${ }^{22}$.

La propaganda patriótica iniciada en abril de 1821 con la impresión en Huaura de El Pacificador del Perú significará el punto de partida de la demolición del liberalismo hispánico como lenguaje político, el mismo que trató de defender y popularizar de modo inocuo El Triunfo de la Nación. En su primer número el periódico editado por Bernardo Monteagudo dejará claramente sentado que la revolución iniciada por Rafael de Riego, si bien había cambiado la faz política de España, ella sería su ruina por ser extremadamente liberal, del mismo modo que no podía ser admitida por los americanos por mantenerlos en su antigua subordinación colonial:

se ha insultado nuestra razón, queriendo persuadirnos que podemos ser felices, adoptando un proyecto que va a hacer desgraciada a la misma España, pues respecto de ella peca tanto por exceso de liberalidad, como abunda en restricciones hacia nosotros ${ }^{23}$.

El periódico enfatiza que lo que ha reportado el triunfo liberal en España es dar pie a la insubordinación de los militares contra la autoridad en Madrid y América, y en este último caso «basta observar que el objeto de sus esfuerzos en el Nuevo Mundo, no es hoy cumplir con los deberes de vasallaje o la lealtad

22 CDIP, Periódicos, XXIII/1: XXII.

23 El Pacificador del Perú, 10 de abril de 1821. 
que decantan, sino disputarse el poder de adquirir una fortuna, que creen más segura, cuanto la anarquía de la Península los pone al abrigo de toda responsabilidad ${ }^{24}$. Como ejemplo de esta tendencia destacó el golpe perpetrado por los generales reunidos en Aznapuquio contra Pezuela. Estas observaciones resumen la forma en que el tándem formado por San Martín y Monteagudo iba a iniciar una vez establecido el Protectorado el desmontaje del liberalismo hispánico. Por un lado, se trataba de destacar las noticias procedentes de España en que se advirtiera el desgobierno que generaba un liberalismo incontrolado $\mathrm{y}$, por otro lado, se requería insistir en que la única alternativa política que los peruanos tenían para gozar de su libertad era proclamar y defender su independencia.

\section{LA PRENSA EN TIEMPOS DEL PROTECTORADO Y EL CONGRESO \\ CONSTITUYENTE DE 1822 Y EL DESCRÉDITO DEL LIBERALISMO ESPAÑOL}

Tras la salida de Lima del virrey La Serna y sus tropas se proclamó la independencia el 28 de julio de 1821 y se estableció el Protectorado con San Martín a la cabeza. El ministro de Guerra y Marina, y más tarde también ministro de Gobierno y Relaciones Exteriores, Bernardo Monteagudo, se convirtió en el hombre fuerte de este régimen ${ }^{25}$. Uno de los mecanismos de que se valió para afianzar su poder fue controlar buena parte de la maquinaria discursiva del Protectorado. El 13 de octubre de 1821 San Martín refrendaba el decreto de Libertad de Imprenta en el que se declaraba que todo individuo podía publicar libremente sus opiniones sin estar sujeto a censura previa. Además se establecía una Junta Conservadora de la Libertad de Imprenta, integrada por dieciocho individuos, para perseguir a los que atacaran la religión del Estado o la moral pública, incurriesen en el crimen de sedición o traición y difamasen a una persona. Como era de esperar los miembros de esa Junta fueron todos personajes afines al proyecto monárquico de San Martín. Asimismo, los periódicos que circularon confirman lo que François Xavier Guerra calificó como la persistencia de la «unanimidad» del Antiguo Régimen en la opinión pública de las nuevas naciones americanas ya que nadie se atrevió a contradecir la palabra del gobierno ${ }^{26}$. Por ello se puede decir que hubo libertad de imprenta para los que coincidieron con el proyecto del Protectorado. En ese contexto, Monteagudo tomó el control de dos periódicos que fueron claves para su pro-

24 El Pacificador del Perú, 30 de abril de 1821.

25 Una reciente biografía de Monteagudo en McEvoy, 2006: 59-86.

26 Guerra, LXII/225 (Madrid, 2002): 357-384. 
yecto de fomentar un sistema de gobierno monárquico constitucional: la Gaceta del Gobierno de Lima independiente, órgano oficial del Protectorado que comenzó a editarse el 16 de julio de 1821, y El Sol del Perú, periódico que promovió la Sociedad Patriótica a partir del 14 de marzo de 1822. Por no incluir este último ninguna mención a la realidad española, en los párrafos que siguen se analizará exclusivamente la trayectoria discursiva del periódico oficial del Protectorado.

La Gaceta del Gobierno de Lima no solo fue el periódico donde se publicaban los decretos y demás noticias de carácter oficial del Protectorado, sino también el medio a través del cual se filtraron noticias de un indudable contenido doctrinario. Con cierta frecuencia se publicaban y comentaban los partes oficiales que daban cuenta de los avances de la expedición militar patriota por el territorio que las tropas de San Martín controlaban. Este periódico también fue utilizado para formar una opinión crítica entre los lectores con relación a las acciones reprobables emprendidas por el gobierno virreinal de La Serna y sus principales generales contra la población que simpatizaba con los patriotas. Por último, continuando la ofensiva discursiva iniciada en El Pacificador del Perú, no podía omitirse el dar cuenta de la situación calamitosa en que se hallaba la España de Fernando VII dominada por las pasiones políticas impuestas por los liberales más radicales. La Gaceta se valió de toda una red de periódicos hispanoamericanos (en especial de Argentina, Chile, Colombia, en ese orden de importancia) de los que extractaba sus noticias para informar sobre la situación en la ex metrópoli.

La ofensiva de la Gaceta contra el Trienio Liberal se hizo evidente ya en los primeros números al identificarse a las Cortes como un refugio de los enemigos de la religión católica. Esta noticia procedía del periódico Miscelánea Chilena y su objetivo no era otro que censurar el proyecto de concordato con el Vaticano aprobado en las Cortes para promover la reforma del clero. Se trataba de una serie de medidas en las que destacaba la secularización de todos los institutos religiosos, la libertad para que los clérigos se pudieran casar, la introducción del divorcio civil y político, la supresión de todas las festividades religiosas y la prohibición de que España reconociera los concilios convocado por el Vaticano. El comentario del anónimo autor de esta noticia dejaba en claro que los diputados españoles al atacar a la Iglesia habían violado su propia Constitución y, por tanto, habían hecho bien las ex colonias americanas en independizarse, porque ellas serían en adelante las naciones que sostendrían la verdadera religión: «he aquí el catolicismo en que ha venido a parar esa nación perjura ante la Constitución misma en que sancionó como base fundamental el ser católica, apostólica, romana. ¡Gracias a Dios que no pertenecemos ya a semejante nación! La religión va a refugiarse como en piadoso asilo en nuestros 
países» ${ }^{27}$. Esta noticia sobre el Concordato fue complementada por una extensa información aparecida una semana después en Los Andes Libres en donde se reproducía el texto íntegro de la «teoría para la organización de una concordata que la nación española puede celebrar con S. S. para la reforma del clero» presentada y aprobada en las Cortes $^{28}$. Esta comunicación vino precedida de una nota tomada de la Miscelánea Chilena en el que se recordaba que los españoles en 1815 habían justificado su ataque al autonomismo chileno como una lucha contra la impiedad y el libertinaje. El autor de la misma solicitaba al lector comparar la conducta religiosa observada por Chile en once años de revolución con la que ahora experimentaba España «y decídase cual de los dos pueblos merece el nombre de piadoso y adicto a su religión; y cual el de innovador y destructor de la religión de sus mayores»» ${ }^{29}$.

El descrédito del liberalismo realmente existente en España por su ataque a la religión al que apeló Monteagudo dentro de la Gaceta procuró, al mismo tiempo, congraciarse con la mentalidad conservadora y cortesana de la elite limeña. No solo se garantizó a esta que el Protectorado salvaguardaría el catolicismo sino también se evitaría que en el Perú se implantase un sistema de gobierno dominado por la plebe, que es como se define políticamente al régimen que se ha establecido en España desde $1820^{30}$. En efecto, en noviembre de 1821 la Gaceta de Lima dio cuenta en su sección «Noticias de España» que:

el populacho sigue dominando; y a centenares son desterradas las personas más respetables [...] Los propietarios en especial son el blanco de la venganza popular. Las instituciones actuales participan de esas seductoras pero impracticables teorías filosóficas de gobernación, por cuyo establecimiento se ha vertido ya bastante sangre, sin que hayan sido susceptibles de la menor consistencia ${ }^{31}$.

Esta información se completaba con la insurrección de los insurgentes serviles de Castilla liderados por el fraile Jerónimo Merino Cobs, contra el gobernador y ex guerrillero liberal Juan Martín Díaz, conocido como El Empecinado ${ }^{32}$. La Gaceta destacaba el estado de práctica guerra civil entre serviles y li-

27 Gaceta del Gobierno de Lima independiente, 29 de julio de 1821.

28 El proyectado Concordato no solo no se suscribió sino que dio pie para que estallaran guerrillas favorables al retorno del absolutismo y la Inquisición coordinadas por los curas. Para un análisis de esta coyuntura ver Sánchez Herrero, 2008: 295-297.

29 Los Andes Libres, 7 de agosto de 1821.

30 Sobre el miedo a la plebe entre la nobleza criolla y española a fines del siglo XVIII y principios del siglo XIX continúa siendo fundamental el estudio de Flores Galindo, 1994, y como complemento el trabajo de O'Phelan, 2005: 123-138.

31 Gaceta del Gobierno de Lima, 10 de noviembre de 1821.

32 Gil Novales, 2010, II: 1872-1874. 
berales que se experimentaba en Castilla y Galicia, lugar este último en donde «el gobernador militar Espoz y Mina a imitación del revolucionario francés Barrere quería pasarlos [a todos los proscriptos serviles] por las armas $\rangle^{33}$. La Gaceta sutilmente interiorizaba así en los lectores que los peligros de la irreligión, la guerra civil y el gobierno del terror a lo Robespierre estarían siempre alejados de la naciente nación gracias a la independencia y su Protector.

De la Gaceta de Bogotá su par limeño reprodujo la noticia comentada acerca de la amnistía acordada en las Cortes a los «disidentes de América» el 27 de septiembre de 1821. Se ironizaba sobre «la más grande beneficencia, justicia y filantropía» de esta gracia por la cual se concedía un olvido general a los rebeldes al rey en tanto que jurasen la Constitución. Siempre en tono sarcástico, la noticia deriva hacia la serie de «beneficios» de que los americanos se privarán de no hacer caso a la oferta de volver a integrarse al seno de la monarquía, esto es, la de solventar económicamente a una nación arruinada con una deuda de 14 mil millones de reales y la de socorrer a un Estado carente de armas, con un ejército desmantelado y unos sueldos militares de limosna. El comentario final invita a los lectores a tomarse la propuesta de las Cortes en serio e interiorizar que si se aceptara el indulto y se jurara la Constitución, los americanos «quedaríamos divididos en blancos y pardos, y quedaríamos sufriendo todas las cargas como ciudadanos, pero no disfrutando de todos los derechos de Ciudadanos Españoles» ${ }^{34}$. Un comentario burlesco similar mereció en el periódico el discurso de Fernando VII al concluir las sesiones de las Cortes en Madrid el 30 de junio de 1821. El texto es íntegramente reproducido sin comentarios hasta la frase final en que se hace sobresaltar con mayúsculas y múltiples signos de exclamación desaprobatoria la afirmación de que los españoles de ambos hemisferios, a los que el monarca se dirigía, debían estar convencidos de que él nada desea tanto como su felicidad «fundada sobre la integridad de la monarquía y la observancia de la Constitución ${ }^{35}$. El rechazo visceral a la Constitución gaditana se hace aún más manifiesto en un artículo en el que se reproduce un extracto del escrito «Resultados de la revolución de España con concepto a su influjo sobre la América» del abate de Pradt. En un momento de su reflexión este personaje resalta como mucho más benefactora para América la fracasada Constitución aprobada por Napoleón Bonaparte porque «la Constitución española hecha en Bayona en 1808 era la iniciativa del paso de la subordinación absoluta a la metrópoli, a la igualdad con ella. [Por el contrario] las Cortes de Cádiz han tratado con altivez y dureza a las co-

33 Gaceta del Gobierno de Lima, 10 de noviembre de 1821.

34 Ibidem, 19 de septiembre de 1821.

35 Ibidem, 5 de enero de 1822. 
lonias de América; estas Cortes les han hecho la guerra y los agentes españoles se han mostrado muy crueles» ${ }^{36}$.

La situación de caos social en la España liberal resaltada por Monteagudo en la Gaceta iba a ser utilizada por este como un pretexto para aplicar una de sus medidas más controvertidas como fue el decreto sancionado el 25 de enero de 1822 en el que se acordaba el destierro y confiscación de bienes de los españoles solteros de Lima, incluyéndose en el mismo a los eclesiásticos seculares y regulares, que no tuviesen carta de ciudadanía ${ }^{37}$. En la Gaceta se justificó esta medida como un gesto recíproco a la expulsión de los representantes americanos de las Cortes y de España por un gobierno liberal sometido a la «plebe», noticia que fue reproducida de la Miscelánea del Istmo de Panamá. En efecto, en esta se resaltaba que los representantes colombianos y todos los americanos que participaron en las Cortes fueron expulsados «por atribuirles el bajo pueblo los movimientos interiores de las provincias, para no dejar a la España organizar su gobierno bajo el orden constitucional $\aleph^{38}$. Monteagudo no perdió ocasión para añadir como comentario que en el Perú, a diferencia de lo ocurrido en España:

razones políticas fundadas en justicia, y dictadas por la experiencia de los sucesos, movieron al gobierno a usar de un sobrio rigor, limitándose [la expulsión] solo a los solteros. Lo contrario se ha practicado en la península, sin que el carácter público de algunos americanos residentes en Madrid, haya podido servirles de salvaguarda contra la antipatía de una nación, que renuncia a todo cálculo, cuando se acuerda que la América está ya fuera de las garras del León que simboliza su carácter ${ }^{39}$.

Aún tuvo tiempo Monteagudo antes de producirse su caída política a fines de julio de 1822 de incidir, a través de la Gaceta, en la terquedad de las Cortes de Madrid de no solo negar la independencia como un hecho irreversible sino en insistir ilusoriamente en formular proyectos de pacificación irrealizables. Uno de estos últimos fue el que se tomó de la Gaceta Ministerial Extraordinaria de Chile que daba cuenta de la proposición de una comisión de las Cortes de dividir la América española en tres grandes secciones (Nueva España; Venezuela, Cundinamarca y Quito; Perú, Chile y el Río de la Plata) donde se establecerían asambleas de Cortes, el rey elegiría tres representantes para ejercer el poder ejecutivo en cada una y, en retribución, los americanos se comprome-

36 Gaceta del Gobierno de Lima, 2 de enero de 1822.

37 CDIP, Obra de gobierno y epistolario de San Martín, XIII/1: 366. De la medida se excluyó a los ancianos mayores de 60 años, a los enfermos imposibilitados de viajar y a los que «por su muy notoria y acreditada conducta merezcan se haga una excepción extraordinaria».

38 Gaceta del Gobierno de Lima, 27 de febrero de 1822.

39 Idem. 
terían a abonar a Madrid altas contribuciones por esa autonomía ${ }^{40}$. El comentario añadido en el periódico oficial a esta propuesta fue considerarla como una «afectación chocante e imbécil»» ${ }^{41}$. Pero la influencia del ministro argentino en el periódico oficial no iba a prolongarse más que otros tres meses. El motín de Lima del 24 y 25 de julio de 1822 que estalló contra el «despotismo» de Monteagudo y que fue liderado por el cabildo de la capital, los representantes recientemente nombrados al Congreso constituyente y el presidente del departamento de Lima, José de la Riva Agüero, culminó con la destitución y exilio de este a Guayaquil ${ }^{42}$.

Excluido del escenario Monteagudo, la Gaceta en las últimas semanas de vida del Protectorado no volvió a proporcionar información sobre España. Esta solo se reanudó después de establecerse el Congreso Constituyente el 20 de septiembre de 1822, instancia ante la cual el general San Martín hizo renuncia de su cargo de Protector y optó por retornar a Buenos Aires. Fue este el momento en que se produjo la transición del inaplicable proyecto monárquico constitucional a un sistema republicano liderado dentro del Congreso por figuras como José Faustino Sánchez Carrión y Francisco Javier de Luna Pizarro. ¿Afectó esta radical transformación del lenguaje político al discurso sobre la realidad española que propagaba la Gaceta? La respuesta es un no condicionado. Las fuentes de las que se alimentó el periódico oficial peruano para referirse a la crisis política que vivía España siguieron siendo las mismas que en la época de Monteagudo, es decir, se recurrió a las noticias publicadas en periódicos argentinos, chilenos y colombianos. Lo que sí se advierte como un cambio respecto a la etapa del Protectorado, es la erradicación de conceptos como gobierno del bajo pueblo y triunfo de la impiedad religiosa que fue vital para que el ex ministro de San Martín justificara la distinción del proyecto monárquico constitucional que este último deseaba implantar en Perú.

En octubre de 1822 la Gaceta incluyó una noticia publicada por el Argos de Buenos Aires sobre las «varias ocurrencias sangrientas que prueban el estado de fermento en que aún se halla mucha parte de la península». En ella se reseñaban los desórdenes alentados por los liberales exaltados contra las autoridades civiles y militares moderadas que estallaron en Valencia aunque «aun parecen más graves las guerrillas que hubo en las calles de Pamplona, entre los militares y estudiantes y el pueblo los días 17,18 y 19 [de marzo de 1822] con ocasión del grito de viva Riego, a que otros contestaban viva el Emperador

40 Sobre la contradictoria política hacia la América española de las Cortes y de otras instancias políticas del Trienio Liberal, ver el artículo de Ascensión Martínez en este dossier.

41 Gaceta del Gobierno de Lima, 27 de abril de 1822.

42 McEvoy, 1999: 37-47. 
Riego» ${ }^{43}$. A continuación, la noticia enfatizaba que el propio Riego, que por entonces era presidente de las Cortes, desaprobó esas arengas e incluso afirmó al secretario de Gracia y Justicia que él nunca lideraría a los descontentos y exaltados por ir en contra de la unidad nacional. A fines de noviembre, nuevamente se recurrió al Argos de Buenos Aires para divulgar una noticia confeccionada a partir de extractos de cartas particulares escritas en Madrid en junio de 1822. Estas daban cuenta del aislamiento y el cordón sanitario ideológico impuesto a España por la Francia de Luis XVIII, del estallido de levantamientos de los liberales exaltados en Cataluña y Galicia rápidamente conjurados, del conflicto abierto entre las Cortes y el gobierno moderado y de la lucha de facciones dentro de esta misma asamblea legislativa al punto tal que «hay un tal Alcalá Galiano, y una media docena como él, que son peores que los de la Junta de Salud Pública de París el año de 93» ${ }^{44}$. Como era de esperar la divulgación en el Perú de la entrada en el poder de los liberales exaltados no mejoró el concepto formado sobre el discurrir de la España constitucional. Más bien provocó el efecto de profundizar el rechazo al desorden social promovido por unos políticos considerados como seguidores de los jacobinos. Así, en unas «Reflexiones», probablemente redactadas por el editor de la Gaceta, este resaltó que cada vez eran más frecuentes las violentas contradicciones políticas y sociales que experimentaba el gobierno español y no parecía que ello se pudiera revertir sino todo lo contrario: guerras civiles que sin duda traerán la ruina de la nación, es el fruto que han sacado los españoles de su reforma, prueba clara de que no tuvieron el tino necesario para hacerla ${ }^{45}$.

De la Abeja Argentina en diciembre la Gaceta reproduce la rebelión que a fines de mayo de 1822 encabezó en Valencia el «turbulento Elío», el ex gobernador de la plaza de Montevideo que lideró la Junta de gobierno fidelista y conservadora establecida en 1808 , que ahora también se situaba como uno de los representantes más conspicuos de la lucha contra los liberales. Esta información se completó con el anuncio del estallido de una revuelta en Aranjuez al grito de «viva el rey absoluto» ${ }^{46}$. Sobre este último suceso que no era otro que el levantamiento servil del 7 de julio de 1822, la Gaceta dio cuenta de un modo pormenorizado en los ejemplares publicados el 18, 25 y 28 de diciembre de ese mismo año. El lector pudo conocer que la rebelión implicó a cuatro batallones en Madrid que se pronunciaron para devolver a Fernando VII su condición de rey absoluto. Seguidamente, se destacó que dicho levantamiento

43 Gaceta del Gobierno de Lima, 9 de octubre de 1822.

44 Ibidem, 27 de noviembre de 1822.

45 Idem.

46 Ibidem, 7 de diciembre de 1822. 
pudo ser conjurado gracias al apego a la Constitución de generales como Pablo Morillo, el militar que reconquistó Nueva Granada en 1815, y Pedro José Ballesteros. Pero este resultado en el que se reconocía que por esta vez los partidarios de la Constitución habían derrotado a los nostálgicos de la «inquisición», no podía ser interpretado como un triunfo definitivo, sobre todo porque se advertía que entre los conspiradores había servidores vinculados con la casa del rey y era de sospechar que Fernando VII conociera esta trama. Por eso el redactor de esta noticia concluyó entre cauteloso y pesimista que:

doloroso es a la verdad que los que aconsejan al rey de España, no reconozcan la imposibilidad de que retrograde la revolución, sin que en este retroceso se conmueva de tal manera el edificio social desde cimientos [...] Póngase el rey de buena fe, como nos ofreció en marzo del año 20, al frente de la revolución, española y lejos de temerla, será S. M. temido de cuantas pudieran intentar, o hacerla retroceder o llevarla más allá del punto que la señala la Constitución que juramos en ella ${ }^{47}$.

La postura de la naciente prensa republicana con respecto a la situación del liberalismo español comenzó a expresarse a través de la Abeja Republicana que editó Faustino Sánchez Carrión. Este abogado y político nacido en Huamachuco (Trujillo) resumió la situación de la España constitucional como un breve paréntesis en una nación acostumbrada a hincar las rodillas ante sus autoridades y cuyo rey Fernando VII era inocultable partidario de los españoles enemigos de la libertad porque «con la opinión de ellos, y con sus brazos sumerge [con el decreto del 4 de mayo de 1814] de nuevo el reyno en el abatimiento. Seis años transcurren para que se reanimen Quiroga y Riego. Restituyese el goce de la Constitución; pues todavía hay serviles que pelean por derogarla ${ }^{48}$. En el ejemplar de la Abeja Republicana publicado el 8 septiembre de 1822, Sánchez Carrión insertó un extracto de la Memoria sobre el estado actual de las Américas y medio de pacificarlas publicada en 1821 por Miguel Cabrera de Nevares, y que fuera redactada a instancias del ministro de Ultramar Ramón López Pelegrín. La Memoria fue presentada por este ministro a las Cortes en enero de 1822 como un plan de reconocimiento de la independencia hispanoamericana a cambio de la formación de una confederación que reconociera la autoridad suprema de Fernando VII, propuesta que finalmente no prosperó $^{49}$. La única alusión al documento hecha por el editor fue que daba a conocer la Memoria a sus lectores para que se «conozca la opinión de España

47 Gaceta del Gobierno de Lima, 25 de diciembre de 1822.

48 La Abeja Republicana, 15 de agosto de 1822.

49 Gil Novales, 2010, I: 520. 
sobre nuestra contienda, y nos persuadamos que pronto va a ser reconocida nuestra independencia» ${ }^{50}$.

Al igual que Lima y las provincias del norte, el sur andino peruano dominado por los realistas experimentó innovaciones durante la primera fase de la independencia que afectaron el modo de informarse de sus pobladores. La llegada de la imprenta permitió que por primera vez Cuzco y Arequipa editasen periódicos, libros y folletos políticos, y con ello su cultura política comenzase a cambiar ${ }^{51}$. En contraste con la significativa información que con relación a la situación interna de España dedicó el periódico oficial editado en Lima, en el Cuzco el virrey, legalmente el Jefe Político Superior, José de la Serna a través de su periódico que tituló Gaceta del Gobierno Legítimo del Perú, que circuló desde fines de enero de 1822, proporcionó escasas noticias al respecto ${ }^{52}$. La dificultad que tuvo el gobierno virreinal cuzqueño para obtener noticias fidedignas de lo que estaba ocurriendo en la Península Ibérica solo podía solventarse a partir de una conexión con el imperio portugués del Brasil. Es casi seguro que el virrey estuvo enterado por este canal del enfrentamiento fratricida entre serviles y liberales en la metrópoli. Lo único cierto es que optó por no divulgarlo y más bien se concentró en que el periódico oficial diera a conocer los esfuerzos que se hacían en las Cortes para recuperar los territorios americanos gobernados por «los disidentes» (término que se prefirió usar para el enemigo antes que el de patriotas). En una de esas escasas referencias se publicó en la Gaceta del Gobierno Legítimo la síntesis de unas cartas oficiales procedentes de Río de Janeiro relacionadas con el cambio del gabinete ministerial dispuesto en febrero de 1822 por Fernando VII y que se interpretó como una confirmación de que el régimen constitucional «se consolidaba cada día más en España». Se anunció a los lectores que se habían conformado en diciembre de 1821 las Cortes extraordinarias para tratar en sesiones secretas el estado en que se hallaban la América septentrional y meridional y que se había descartado una resolución en la que se «propuso enviar comisionados a conferir con los caudillos disidentes ${ }^{53}$. Esta aseveración tuvo en parte que rectificarse en el siguiente número al anunciarse que las Cortes habían adoptado el 13 de fe-

50 La Abeja Republicana, 8 de septiembre de 1822.

51 Walker, 1999. Glave, 2004. Cahill, 2002.

52 Dos de las más recientes biografías sobre este virrey han preferido abordar el tema del discurrir del gobierno virreinal del Cuzco desde una perspectiva militar por lo que todavía se carece de un estudio sobre la forma en que La Serna aplicó la Constitución en el sur andino. Ver Albi de la Cuesta, 2009. Marqués de Laserna, 2010. El artículo de Núria Sala i Vila publicado en este mismo dossier confirma que la Constitución se aplicó al menos en la formación de los ayuntamientos constitucionales en el Cuzco, Arequipa y Huamanga.

53 Gaceta del Gobierno Legítimo del Perú, 9 de agosto de 1822. 
brero de 1822 el parecer manifestado por la comisión especial sobre los negocios de América «cual era, que se mandasen comisionados cerca de los gobiernos nuevamente establecidos, [pero] para que se rechazasen todas las proposiciones que fuesen contrarias a la libertad de las personas y seguridad de las propiedades de los españoles y americanos adictos a la causa nacional $\gg^{54}$. También se anunció que en las Cortes se aprobaron las proposiciones del conde de Toreno de anulación del tratado mexicano de Córdoba entre O'Donoju e Iturbide, de renovación de los derechos históricos de España sobre sus posesiones de ultramar y del envío de nuevos refuerzos militares «a todos los puntos que noblemente mantienen sus relaciones con la madre patria». Extrañamente, nada se volvió a comentar de la España liberal en este periódico oficial de los realistas que dejó de circular el 31 de agosto de 1824 .

EL FRACASO DEL TRIENIO LIBERAL EN LA PRENSA PATRIÓTICA DE LOS TIEMPOS DE BOLÍVAR

La caída del segundo experimento constitucional en España se produjo entre abril y octubre de 1823, cuando los llamados Cien Mil Hijos de San Luis, el ejército francés enviado a España por Luis XVIII, acabaron con las Cortes, derrotaron a los liberales moderados y exaltados y restablecieron a Fernando VII como monarca absolutista. La noticia fue conocida en el Perú a principios de 1824. A través de la Gaceta del Gobierno del Perú editada alternativamente en Trujillo y Lima bajo la dictadura de Simón Bolívar se siguió con evidente retraso pero vivo interés el discurrir de un desenlace anunciado por los que consideraban que Fernando VII no subsistiría mucho como monarca constitucional. En la Gaceta del 7 de enero de 1824 se consideró infructuosa la defensa del orden constitucional en Pamplona, San Sebastián y Santoña ante el mayor poder del «plan vil y ratero de guerra adoptado por los franceses». También se daba cuenta que Morillo, Ballesteros y otros generales liberales habían reconocido a la Regencia establecida en Madrid por los franceses hasta el retorno de Fernando VII de Cádiz y «que el gobierno constitucional no existe ${ }^{55}$. Una posterior noticia tomada del Argos de Buenos Aires que a su vez la recabó del periódico Estrella del Brasil, resumió la proclama a los españoles pronunciada por Fernando VII a su salida de Cádiz en uno de cuyos puntos se comprometía a que «en caso de ser precisas algunas alteraciones al pacto fundamental actual, ellas habrían de respetar siempre los derechos nacionales e

54 Gaceta del Gobierno Legítimo del Perú, 31 de agosto de 1822.

55 Gaceta del Gobierno del Perú, 7 de enero de 1824. 
individuales». El editor se valió de este ofrecimiento para comentar que era de desear que este monarca «conociendo sus verdaderos intereses resista a las insinuaciones de la regencia de Madrid, y haga gozar cuanto antes a su pueblo las instituciones verdaderamente liberales y en armonía con el estado de las luces $»^{56}$.

El desenlace del drama español que supuso reconocer la segunda traición de Fernando VII al constitucionalismo coincidió, casi cronológicamente, con otras dos impactantes noticias como fueron, primero, la traición a Bolívar del marqués de Torre Tagle y su paso al bando realista liderado por el general Rodil en la fortaleza de El Callao y, segundo, el desconocimiento de la autoridad del virrey La Serna por parte del general Pedro Antonio de Olañeta en el Alto Perú. En un suelto titulado «Noticia importante para el virrey La Serna», se anunciaba que el rey, una vez abolida la Constitución, se había congraciado con el general Pezuela y que este podía ser nombrado ministro de guerra o reelegido virrey del Perú y «sabemos igualmente que es horrible la emigración española después de la restitución de Fernando absoluto. Mujeres, niños, familias enteras dejaban las costas de España ${ }^{57}$. En otro suelto en el mismo ejemplar se anunciaba que por conductos oficiales se habían embarcado en Gibraltar con destino a Lima personajes relevantes del régimen derruido como José María Pando, último ministro de Estado del gobierno constitucional, y Felipe Bauzá, ex director del Observatorio Astronómico de Madrid. Si el primer caso era cierto el segundo no lo fue ya que Bauzá más bien emigró a Inglaterra. Finalmente, de El Sol de México la Gaceta reprodujo una noticia en el que se censuraba el fusilamiento de Rafael de Riego con el siguiente epígrafe: «iRiego ha muerto...! El atroz, el infame, el pérfido, el detestable, y espureo Fernando VII ha consumado la serie de sus delitos. La sangre del hijo de Padilla ha empapado la tierra a que dio libertad» ${ }^{58}$. El monarca español en adelante pasaría a ser el blanco predilecto de los ataques de la prensa peruana.

Para culminar el desmontaje del liberalismo hispánico había que resaltar en el periódico oficial cómo habían reaccionado frente a la vuelta al absolutismo en España tanto La Serna como los dos generales más relevantes que le acompañaban, Valdés y Canterac. El artículo «La hipocrecía sin máscara» reconocía el «roce con el liberalismo» de La Serna cuando estuvo prisionero en Francia, también que el general Valdés pertenecía a la escuela del general Ballesteros y, por tanto, era un liberal frenético y que, por último, que el general Canterac fue servil «y se hizo liberal cuando se incorporó al ejército del Perú capitulan-

56 Ibidem, 21 de enero de 1824.

57 Ibidem, 24 de abril de 1824.

58 Ibidem, 1 de mayo de 1824. 
do con Valdés para dirijir de mancomún a La Serna» ${ }^{59}$. El articulista se concentra en la formación del gobierno virreinal en la sierra y resalta que «estos nuevos enemigos de la revolución americana, con el nombre de liberales, redujeron a los serviles a un estado de tercer orden», alusión que directamente apuntaba al desplazamiento de los pezuelistas. Pero, seguidamente, incide en que la aplicación del sistema constitucional en el sur no pudo revertir la decadencia en la opinión pública de los defensores del Rey, por lo que La Serna en 1823 envió dos comisionados a España para recabar instrucciones de Madrid. Estos llegaron a Gibraltar cuando el rey restableció el absolutismo. Esta nueva coyuntura hizo más precaria la situación de los liberales españoles en el Perú «al paso que mejoraba la [posición] de los serviles». Siempre en versión de la Gaceta, como último recurso, los comisionados de La Serna habrían acordado con el monarca imitar el plan que O'Donoju aplicó para México, esto es, proclamar la independencia del Perú y establecer un imperio de Humahuaca hasta Guayaquil bajo la corona de un príncipe de la casa de Borbón. El anónimo autor del artículo se hacía eco del rumor que señalaba que en ese plan habían colaborado americanos originarios tanto de Cuzco como de Lima y que, además, se sabía del nombramiento de una comisión en Madrid cuya misión sería obtener el apoyo de Estados Unidos a esa solución. Este artículo concluyó con un pequeño suelto insertado en el siguiente número de la Gaceta en el que se daba cuenta que Estados Unidos abiertamente se había declarado a favor de la independencia peruana, por lo que La Serna y sus generales «se determinaron por fin a abrazar el partido del servilismo, como el último arbitrio que les quedaba. Apurados por la España hicieron jurar solemnemente en Lima al Rey absoluto, y se quitaron la máscara ${ }^{60}$. En otras palabras, con la anterior noticia publicada en la Gaceta se procuró demostrar que La Serna y sus generales si bien eran doctrinariamente liberales, antepusieron a ello su acatamiento al absolutismo con el único fin de salvar sus cargos, argumento este que se correspondía con las acusaciones vertidas desde el Alto Perú por el general Olañeta.

El ex constituyente republicano José Faustino Sánchez Carrión, convertido en incondicional partidario de la dictadura de Bolívar, publicó en abril de 1824 el periódico itinerante El Centinela en Campaña, editado sucesivamente en Santiago de Chuco, Huamachuco y Huaraz, con el propósito de que la población peruana apoyara a las tropas colombianas en la última ofensiva contra el ejército realista. Por este medio se conoce su opinión sobre el significado del colapso del segundo momento constitucional español, cuyo fracaso ya había

59 Ibidem, 12 de junio de 1824.

60 Gaceta del Gobierno de Lima, 19 de junio de 1824. 
avizorado en La Abeja Republicana por sostenerse en un monarca que no creía en las virtudes del liberalismo. En el primer número destacó de las noticias procedentes de Londres la que se refería a la situación interna en Madrid a mediados de noviembre de 1823 cuando los liberales eran perseguidos. Constataba que la nueva situación amparada por el monarca era el aumento del influjo político del clero y de los fanáticos partidarios del retorno del absolutismo, y que «en cambio los constitucionales fijan su esperanza, en el de los embajadores extranjeros, mientras que los últimos tal vez ignoran las intrigas de la $\mathrm{ca}$ marilla de Fernando» ${ }^{61}$. Por último, anotaba que en medio de ese irreversible caos político los dos militares liberales más representativos, Morillo y Ballesteros, habían partido al exilio. Por ello el derrumbe liberal era a su entender inevitable. Así lo constató en el siguiente número de El Centinela. En esta ocasión la recepción de varias gacetas procedentes de Inglaterra, Jamaica y La Habana, que daban cuenta de lo que ocurría en Europa hasta el 5 de marzo de 1824, le confirmó que el absolutismo había sido totalmente restaurado en España y que Fernando VII pretendía retornar al statu quo previo a 1820 tal como hizo en 1814. Textualmente censuró al rey por mostrar nuevamente una conducta oportunista y traidora con el propósito de enmascarar su única faz de monarca amante del despotismo y genio de la destrucción:

Fernando ha tenido el ecsecrable descaro de publicar indultos y olvidos, decretos y concesiones; ha contraído empeños nacionales los más solemnes, los más sagrados con los ingleses, americanos y otras naciones, hasta el último de setiembre del año pasado. Todo espontáneamente, según su propia expresión, y luego al día siguiente 1 de octubre, borra todo, anula todo, y dice que nada es de lo que ha sido ${ }^{62}$.

A continuación, El Centinela extrajo de la Gaceta de Madrid el decreto del Consejo de Estado español que confería en adelante a los eclesiásticos y párrocos la labor de vigilar la conducta pública con el auxilio de los jueces reales. Era claro que lo que se quería mostrar era como la corta etapa de la libertad había sido reemplazada por una época de auténtica persecución inquisitorial. Si hasta 1824 la prensa peruana no pudo enfilar cómodamente contra la figura del monarca por ser este cabeza de un experimento liberal, a partir de su retorno al absolutismo más retrógrado le fue sencillo destruir la imagen política de un gobernante déspota con los españoles que además se empecinaba en desconocer la independencia de sus ex colonias.

El último artículo, editado en Huaraz, que el periódico de Sánchez Carrión dedicó a la España de Fernando VII fue tomado del periódico colombiano $\mathrm{El}$

61 El Centinela en Campaña, 22 de abril de 1824.

62 Ibidem, 6 de mayo de 1824. 
Republicano. En este se describían los desmanes provocados por un trono sostenido por el fanatismo conservador y religioso. Las características más notables del nuevo Estado absolutista eran el espionaje y la delación contra los liberales y el servilismo y la ferocidad de los partidarios del Rey. El patriotismo liberal había sido barrido por una moral religiosa que solo sirve para promover la ira y el despecho de los que claman revancha. La venganza, la persecución y el exilio son muestras de la realidad a la que ha quedado reducida España. Sánchez Carrión añade a esta descripción un comentario referido a la conducta presente y futura de Fernando VII al que previamente ha calificado como el rey más feroz, inmoral, impolítico e inepto que ha tenido la monarquía española:

su cetro pesa sobre esa tierra que han regado con su sangre tantos héroes; y desolada y yerta huyó de ella la libertad, y solo han quedado esclavos, ignorantes y perversos. El despotismo no será eterno; pero escudado por el terrorismo, la ceguedad y la impotencia de los que piensan; y resguardado con el poder formidable de las coronas europeas; durará largo tiempo, y entretanto las lágrimas serán el único consuelo de los prófugos, de los libres, y de los pueblos ${ }^{63}$.

Fue en el periódico Nuevo Día del Perú editado en Trujillo por Hipólito Unanue en 1824 en donde se expuso la reflexión más importante sobre el significado histórico del liberalismo hispánico para el Perú. Unanue, médico y cosmógrafo que fue asesor de varios virreyes, entre ellos Abascal, que actuó como delegado del virrey Pezuela en la conferencia de Miraflores de 1820, que asumió como ministro de Hacienda en el Protectorado de San Martín y que, por último, se convirtió en propagandista de la campaña libertadora de Bolívar, escribió, después de producirse el triunfo de las armas patriotas sobre las realistas en la batalla de Junín, un artículo titulado «Los liberales de España» ${ }^{64}$. Este escrito está dividido en tres partes, en la primera se concentra en el exilio de los liberales españoles en Inglaterra, en la segunda opina sobre la trayectoria del liberalismo en el Perú en la época de las Cortes de Cádiz y, finalmente, en la tercera enjuicia el derrotero hacia el fracaso del Trienio Liberal. Resultará fundamental tratar separadamente estas tres partes del artículo para hacerse una idea cabal de cómo Unanue, y con él los políticos peruanos del siglo XIX, pudieron desprenderse de un lenguaje político que había sido parte de su cultura política hasta al menos 1821.

Sobre el exilio de los liberales españoles en Londres, Unanue da cuenta de que poco se debe de lamentar las actuales carencias y sufrimientos de este gru-

63 Ibidem, 15 de junio de 1824.

64 Para la biografía de Unanue ver Cañizares-Esguerra, 1995. Dager, 2000. Warren, 2010. Sobre la casi desconocida actuación de Unanue como ministro de Hacienda, ver el artículo de Dionisio de Haro en el presente dossier. 
po de refugiados, entre los que se hallan diputados en Cortes, generales y eclesiásticos, porque merecen experimentar «la vara del fierro de un rey vengativo para que midan por su opresión la que ha sufrido la desgraciada América en las arbitrariedades; e injusticias de una nación tirana ${ }^{65}$. Esta apreciación se fundamenta en que los liberales españoles fueron al igual que los absolutistas unos políticos orgullosos, mientras tuvieron poder poco aprendieron de la «prudencia y sabiduría» inglesa en materia de liberalismo y en el respeto a la libertad lograda por los hispanoamericanos. Unanue expresa su deseo de que en adelante los exiliados en Inglaterra por estar ahora en el centro de las luces y la sabia política de esa nación verdaderamente filantrópica, logren «depurar su liberalismo de las habitudes vergonzosas del despotismo nacional en que se educaron [...] y que con la antorcha luminosa de la filosofía consigan persuadirse, que es quimera, que es usurpación, que es tiranía todo derecho sostenido con la espada contra los votos de la naturaleza» ${ }^{6}$. Esta definición de los liberales españoles como políticos educados en el hábito del despotismo será fundamental para entender cómo Unanue resumirá lo que a su juicio experimentaron los peruanos en las dos etapas de vigencia del liberalismo hispánico.

Con relación a la época de las Cortes de Cádiz, el médico ariqueño invita figuradamente al lector a recurrir a la consulta de los diarios de las sesiones para confirmar que la decantada Constitución solo sirvió en América para «añadir a las vejaciones el engaño». Con esa afirmación se refería a la falsedad de una época en que si bien se expresaba en las Cortes que había llegado el tiempo de que los españoles americanos defendieran libremente sus derechos y expusieran sus quejas, todo ello terminaba en un desaire y un ataque injustificado a quien criticaba a los gobernantes. Recordaba cómo los primeros ensayos de libertad constitucional trajeron a los americanos la calificación de insurgentes y se justificó con ello el derecho de hacerles volver al orden por la fuerza de las armas. Reconocía a las Cortes de Cádiz la proscripción del derecho de conquista y la calificación de tiranía a todo derecho que no se sustentara en el respeto a la libertad, pero a su vez recordaba que al derrumbarse con tales reconocimientos la única cadena que mantenía vinculada a España con Ultramar, nació la idea de emanciparse de la madre patria. Recalca Unanue que ante este imponderable los diputados españoles dividieron a los americanos en una parte sana (o fiel) y una parte turbulenta (o corrompida), y justificaron la guerra y exterminio de esta última aún a expensas de justificar el vandalismo. Su conclusión de lo anterior era que la concesión de derechos a los

65 Nuevo Día del Perú, 26 de agosto de 1824.

66 Idem. 
americanos equivalía a poner en marcha su independencia, razonamiento que se sustentaba en que los liberales españoles no podían reconocer una igualdad política absoluta: «pensasteis alucinarnos, llamándonos a participar de vuestros derechos, sin entender, que el mismo razonamiento que designaba vuestra dicha en la libertad del gobierno absoluto, marcaba también la nuestra en la libertad absoluta de vuestro gobierno» ${ }^{67}$.

Por último, Unanue en referencia a la segunda etapa del constitucionalismo se preguntó porqué los liberales no habían aprendido la lección de despojarse de «su arrogancia y mezquindad» después de experimentar las calamidades de seis años de absolutismo y ver que lo único que este antiguo régimen aceleró fue la independencia de Colombia, Chile y Argentina. Se refería con lo anterior a lo que definía de escándalo, el que las Cortes reunidas en Madrid en 1820 otorgasen a los americanos una representación de apenas treinta diputados para sus doce millones de habitantes. Recalcaba asimismo que la Constitución que Fernando VII juró sin creer en ella, prohibía el uso del término virrey y lo reemplazaba por el de jefe político superior, pero en Madrid en 1820 se destinaba a Cruz Murgeón con ese título a gobernar en Nueva Granada y Costa Firme. Seguidamente, hacía mención a que el ministro de Ultramar demandaba a los virreyes a que observaran la Constitución como en la Península, pero en las Cortes de 1821 afirmaba que era imprudente practicar la división de poderes en América. Por último, recordó que si el «club de francmasones ambiciosos» que depuso a Pezuela y nombró virrey a La Serna cometió una grave falta constitucional, en las Cortes tal acto fue justificado con el pretexto de que se haría una guerra más viva a los patriotas. Los múltiples ejemplos de agravios arriba relacionados motivaron a Unanue a definir a las Cortes como el sistema en el que «los nombres se mudan, y la substancia de las cosas permanecen [sic]». Era irrebatible para este político peruano que la actuación de los liberales españoles con respeto a América estaba en consonancia con lo practicado por el monarca en su época de gobernante absolutista. Por eso concluyó ironizando sobre el único punto en común en el que coincidió el absolutismo del rey con el liberalismo de las Cortes en septiembre de1823:

¡Ah! Qué bien conocía él [Fernando VII] que en todo le habían los liberales contrariado, menos en el plan de esclavizar la América, cuando, anulando los actos todos de su régimen constitucional, solo exceptuó los decretos que decían relación a las Colonias. ¡Si entenderán bien esto de tiranizar los liberales! ${ }^{68}$.

67 Idem.
68 Idem. 
Unanue al redactar este artículo proporcionó a la memoria histórica peruana el justificativo para renegar del liberalismo español. Equiparando al liberalismo doceañista con el absolutismo, logró que en la mentalidad de los políticos peruanos del siglo XIX se asentase una nueva leyenda negra española.

\section{CONCLUSIÓN}

Entre 1821 y 1823 las gacetas del gobierno así como otros periódicos editados en Lima y otras provincias aledañas cumplieron un papel fundamental en el desmontaje del liberalismo hispánico en el Perú. Pero para alcanzar este propósito los periódicos optaron por una serie de interpretaciones de la realidad española de acuerdo con la coyuntura política que se atravesó (Protectorado, Primer Congreso Constituyente, Junta Gubernativa presidida por La Mar, presidencias de José de la Riva Agüero y del marqués de Torre Tagle y Dictadura de Bolívar) y según el tipo de fuentes que se utilizó (prensa de Chile, Argentina y Colombia independientes). Durante el Protectorado, la prensa que circuló al amparo del decreto de Libertad de Imprenta, y muy en especial La Gaceta del Gobierno controlada por Bernardo Monteagudo, demonizó al liberalismo hispánico como el gobierno de la plebe y de la persecución religiosa en su intención de desmarcar a la misma de la monarquía constitucional ofertada por el general San Martín a la elite que estaría sostenida por una nobleza patriota que garantizaría la protección del catolicismo. El destierro de Monteagudo, el fin del Protectorado y el triunfo definitivo del ideario republicano en el Congreso Constituyente produjo un cambio en esta forma de representación del liberalismo español. El discurso de Monteagudo fue sustituido por uno en el que lo más destacado fue el clima bélico entablado entre liberales y serviles como una pugna respectiva entre los defensores de la libertad y los apologistas de la Inquisición. Ello permitió destacar la figura de Fernando VII como un monarca cuya vocación absolutista haría inclinar la balanza a favor de los serviles. Este discurso fue básicamente confeccionado por el republicano José Faustino Sánchez Carrión, enemigo personal de Monteagudo y detractor de la monarquía constitucional. Por último, la entrada en el escenario peruano de $\mathrm{Si}$ món Bolívar coincidió con la quiebra del Trienio Liberal pronosticada por Sánchez Carrión. Pero correspondería al médico Hipólito Unanue imponer el discurso definitivo de que los liberales si bien defendían las libertades para España compartían con Fernando VII y los absolutistas la conducta despótica 
de mantener esclavizada a América. Todo un giro discursivo sobre las carencias del liberalismo hispánico que sería la representación definitiva y dominante de la España negra en el Perú republicano.

\section{FUENTES IMPRESAS Y BIBLIOGRAFÍA}

\section{Periódicos}

El Triunfo de la Nación (1821).

El Pacificador del Perú (1821).

Gaceta del Gobierno de Lima Independiente (1821-1822).

Gaceta del Gobierno Legítimo del Perú (1822-1823).

Gaceta del Gobierno del Perú (1822-1824).

La Abeja republicana (1821-1822).

El Centinela en Campaña (1823).

Nuevo Día del Perú (1824).

\section{Bibliografia}

Albi de la Cuesta, Julio, El último virrey, Madrid, Ollero y Ramos editores, 2009.

Aljovín de Losada, Cristóbal y Jacobsen, Nils (eds.), Cultura política en los Andes (1750-1950), Lima, Universidad Nacional Mayor de San Marcos e Instituto Francés de Estudios Andinos, 2007.

Aljovín de Losada, Cristóbal, Caudillos y constituciones. Perú: 1821-1845, Lima, Pontificia Universidad Católica del Perú y Fondo de Cultura Económica, 2000.

Barthèlemy, Rodolfo G., «El marquesito» Juan Díaz Porlier: "General que fue de los ejércitos nacionales» (1788-1815), Santiago, Universidad de Santiago, 1995, 2 vols.

Cahill, David, From Rebellion to Emancipation in the Andes: Soundings from Southern Peru, 1750-1830, Amsterdam, CEDLA/Aksant, 2002.

Cañizares-Esguerra, Jorge, «La utopía de Hipólito Unanue: comercio, naturaleza y religión en el Perú», en Cueto, Marcos (ed.), Saberes andinos. Ciencia y tecnología en Bolivia, Ecuador y Perú, Lima, Instituto de Estudios Peruanos, 1995: 91-108.

Chiaramonti, Gabriella, Ciudadanía y representación en el Perú (1808-1860). Los itinerarios de la soberanía, Lima, Universidad Nacional Mayor de San Marcos y Oficina Nacional de Procesos Electorales, 2005.

Colección Documental de la Independencia del Perú (CDIP), XXIII Periódicos, 1, Lima, Comisión Nacional del Sesquicentenario de la Independencia del Perú, 1973. 
Colección Documental de la Independencia del Perú (CDIP), XIII, 1, Obra de gobierno y epistolario de San Martín, Lima, Comisión Nacional del Sesquicentenario de la Independencia, 1974.

Dager, Joseph, Hipólito Unanue o el cambio en la continuidad, Lima, Convenio Hipólito Unanue y Convenio Andrés Bello, 2000.

Fernández Sarasola, Ignacio, Poder y libertad: Los orígenes de la responsabilidad del Ejecutivo en España (1808-1823), Madrid, Centro de Estudios Políticos y Constitucionales, 2001.

Flores Galindo, Alberto, La ciudad sumergida. Aristocracia y plebe en Lima, 17601830, Lima, Editorial Horizonte, 1994.

Gamio Palacio, Fernando, La municipalidad de Lima y la emancipación, 1821, Lima, Concejo Provincial de Lima, 1971.

Gil Novales, Alberto, Diccionario biográfico de España (1808-1833). De los orígenes del liberalismo a la reacción absolutista, Madrid, Fundación MAPFRE, 2010, 3 tomos.

Gil Novales, Alberto, El trienio liberal, Madrid, Siglo XXI editores, 1980.

Glave, Luis Miguel, La república instalada. Formación nacional y prensa en el Cuzco, 1825-1839, Lima, Instituto de Estudios Peruanos, 2004.

Gómez-Reino y Carnota, Enrique, Aproximación histórica al derecho de la imprenta y de la prensa en España (1480-1966), Madrid, Instituto de Estudios Administrativos, 1977.

Guerra, François-Xavier, «"Voces del pueblo". Redes de comunicación y orígenes de la opinión en el mundo hispánico (1808-1814)», Revista de Indias, LXII/225 (Madrid, 2002): 357-384.

La Parra, Emilio, Los cien mil hijos de San Luis. El ocaso del primer impulso liberal en España, Madrid, Editorial Síntesis, 2007.

Laserna, marqués de la, José de la Serna. Ultimo virrey español, Madrid, Editorial Akrón, 2010.

Martínez Riaza, Ascensión, La prensa doctrinal en la independencia del Perú, 18111824, Madrid, Instituto de Cooperación Iberoamericana, 1985.

McEvoy, Carmen, «De la comunidad retórica al Estado-Nación: Bernardo Monteagudo y los dilemas del republicanismo en "América del Sud": 1811-1822», José Nun y Alejandro Grimson (comps.), Convivencia y buen gobierno: nación, nacionalismo y democracia en América Latina, Buenos Aires, Edhasa, 2006: 59-86.

McEvoy, Carmen, «"Seriamos excelentes vasallos y nunca ciudadanos”: prensa republicana y cambio social en Lima, 1791-1822», Jaksic, Iván (ed.), The Political Power of the Word: Press and Oratory in Nineteenth-Century Latin America, London, Institute of Latin American Studies, 2002. 
McEvoy, Carmen, Forjando la nación. Ensayos de historia republicana, Lima, Pontificia Universidad Católica del Perú y The University of the South Sewanee, 1999.

Nateiu, Anselmo, Reflexiones políticas escritas bajo el título de Instinto Común por el ciudadano Tomas Paine y traducidas abreviadamente por Anselmo Nateiu, indigena del Perú, Lima, en la Imprenta del Río, año de 1821.

O’Phelan, Scarlett, «La construcción del miedo a la plebe en el siglo XVIII a través de las rebeliones sociales», Rosas Lauro, Claudia (ed.), El miedo en el Perú. Siglos XVI al XX, Lima, Seminario Interdisciplinario de Estudios Andinos y Pontificia Universidad Católica del Perú, 2005: 123-138.

Paniagua, Valentín, Los orígenes del gobierno representativo en el Perú. Las elecciones (1809-1826), Lima, Pontificia Universidad Católica del Perú-Fondo de Cultura Económica, 2003.

Peralta Ruiz, Víctor, En defensa de la autoridad. Política y cultura bajo el gobierno del virrey Abascal. Perú 1806-1816, Madrid, CSIC, 2002.

Peralta Ruiz, Víctor, La independencia y la cultura política peruana 1808-1821, Lima, Instituto de Estudios Peruanos y Fundación M. J. Bustamante de la Fuente, 2010.

Sánchez Herrero, José, Historia de la Iglesia en España e Hispanoamérica: desde sus inicios hasta el siglo XXI, Madrid, Silex, 2008.

Sobrevilla, Natalia, «Batallas por la legitimidad: constitucionalismo y conflicto político en el Perú del siglo XIX (1812-1860)», Revista de Indias, LXIX/246 (Madrid, 2009): 101-128.

Walker, Charles, De Tupac Amaru a Gamarra. Cusco y la formación del Perú republicano 1780-1840, Cuzco, Centro Bartolomé de las Casas, 1999.

Warren, Adam, Medicine and Politics in Colonial Peru. Population Growth and the Bourbon Reform, Pittsburgh, Pittsburgh University Press, 2010.

Fecha de recepción: 30 de marzo de 2011

Fecha de aceptación: 18 de julio de 2011 


\section{The pen against the Cortes and the Throne. The Press and the dismantling of Hispanic liberalism in Peru, 1821-1824}

Through analysis of the discourse of the press during the period of independence, mainly published in Lima, this article will show how it was possible to extirpate Hispanic liberalism from Peruvian political culture. It will be argued that the second period of Spanish constitutionalism known as the Liberal Triennium was easy for newspapers to represent not only as a period of intolerance of Latin American independence but as a plebeian government ready to bring down enlightened nobility and religion, and a system in which servile absolutists and both moderate and extremist liberals shared with Ferdinand VII a congenitally despotic form of conduct. The article is divided into three sections corresponding to the period of the Protectorate, the establishment of the Congreso Constituyente and the dictatorship of Simón Bolivar.

Key words: Press; Liberal Triennium; Hispanic liberalism; Peru; Protectorate; Bernardo Monteagudo; Congreso Constituyente; José Faustino Sánchez Carrión; Hipólito Unanue. 